\title{
Pengembangan Sistem Informasi Surveilans Leptospirosis Di Dinas Kesehatan Kota Semarang
}

\author{
Charisna Neilal Muna*, Farid Agushybana**, Mursid Raharjo** \\ *Suyatno Farm Kabupaten Semarang \\ **Fakultas Kesehatan Masyarakat, Universitas Diponegoro, Semarang \\ Email: charisnamuna@gmail.com
}

\section{ABSTRACT:}

Leptospirosis cases are still a concern, especially in tropical countries, such as Indonesia. Semarang is one of the cities with an increase in leptospirosis in the last 2 years. Epidemiology surveillance is carried out in order to control leptospirosis. The problems found in leptospirosis surveillance are the incompleteness of the data management, the lack of information and case mapping, also the lack of user access towards data availability. The purpose of this study is to develop the leptospirosis surveillance information system with GIS in supporting control based on environment risk factor at Semarang Health Department. The method of this study is research action with qualitative approach, and the system development uses FAST method. The result of this study shows that the quality of the information according to the facility, completeness, availability, accurateness, and time accuracy aspect has been better and able to overcome the previous problem to support the control. Leptospirosis surveillance information system can be applied in health services to report the case directly, so that the data and information reach are wider, more accurate, and more efficient.

Keyword: leptospirosis surveillance, FAST, information system

\section{PENDAHULUAN}

Leptospirosis merupakan salah satu penyakit tular vektor dan zoonosis yang masih menjadi masalah kesehatan di dunia. Angka insidensi penyakit leptospirosis di dunia sebesar $0,1-1$ per 100.000 per tahun, dengan kejadian luar biasa dapat mencapai 100 per 100.000 per tahun. ${ }^{1}$ Di Indonesia, terdapat 6 provinsi di tahun 2016 yang melaporkan adanya kejadian leptopirosis dengan total sebanyak 833 kasus $(\mathrm{CFR}=7,44 \%)$. Provinsi Jawa Tengah merupakan provinsi dengan kejadian leptospirosis kedua di Indonesia tahun 2016. ${ }^{2}$ Kota Semarang menjadi salah satu kota yang tidak terlepas dari kejadian leptospirosis. Kasus leptospirosis di Kota Semarang meningkat dari tahun 2016 
sebanyak 42 kasus $(\mathrm{CFR}=14,3 \%)$ menjadi 55 kasus $(\mathrm{CFR}=25,4 \%){ }^{3}$

Leptospirosis adalah salah satu penyakit yang menjadi prioritas untuk dilakukan surveilans epidemiologi. Pengolahan dan penyajian data surveilans penyakit perlu dilaksanakan dalam bentuk peta yang bermakna secara epidemiologi. Laporannya pun sebaiknya dapat mempresentasikan diagnosis, status, perkiraan peningkatan dan penyebaran KLB, serta rencana penanggulangannya. ${ }^{4,5}$

Surveilans epidemiologi tidak hanya mempertimbangkan faktor sosial ekonomi, tetapi juga konteks dimana mereka dianalisis. ${ }^{6}$ Pada surveilans leptospirosis, satu skala geografis lebih memadai untuk menunjukkan hubungan antara kejadian leptospirosis dan sekelompok faktor untuk menilai risiko leptospirosis pada populasi tertentu dengan benar. ${ }^{7}$ Faktor lingkungan merupakan indikator yang penting untuk mengidentifikasi dinamika penularan leptospirosis di suatu wilayah. ${ }^{8}$ SIG merupakan sistem aplikasi yang dapat mendukung surveilans kesehatan berbasis geospasial dengan baik dan efektif ${ }^{9}$

SIG dapat berperan dalam pemetaan penyakit untuk menyelidiki penyebaran spasial infeksi leptospirosis, mengidentifikasi faktor risiko geografis dan lingkungan, serta meningkatkan pemahaman tentang transmisi penyakit leptospirosis. Output berupa peta yang dihasilkan oleh SIG akan memfasilitasi pemahaman tentang distribusi geografis leptospirosis di tingkat daerah dan faktor risiko lingkungannya. ${ }^{10}$

Dinas Kesehatan Kota Semarang melakukan kegiatan surveilans leptospirosis secara aktif dan pasif sebagai langkah penanggulangan leptospirosis. Surveilans leptospirosis dilakukan dengan mengumpulkan data kejadian penyakit dari pelayanan kesehatan dengan menggunakan formulir pelacakan leptospirosis. Namun, pencatatan data yang dimasukkan ke dalam sistem dinilai kurang lengkap. Pengolahan dan penyajian data leptospirosis terutama peta persebaran penyakit juga kurang informatif. Selain itu, sistem manajemen basis data untuk leptospirosis belum diterapkan, sehingga mengakibatkan kesulitan dan membutuhkan waktu lebih lama dalam mencari, menyimpan, dan mengakses data.

Tujuan dari penelitian ini adalah pengembangan sistem informasi surveilans leptospirosis di Dinas Kesehatan Kota Semarang.

\section{METODE PENELITIAN}

Jenis penelitian yang dilakukan adalah research action dengan pendekatan kualitatif. Observasi dan wawancara dilakukan untuk menganalisis sistem yang berjalan saat ini, mengidentifikasi permasalahan dan kebutuhan pengguna, serta mengukur kualitas informasi. Pengembangan sistem dilakukan dengan metode FAST (Framework for the Application of System Techniques) dengan tahapan definisi lingkup, analisis masalah, analisis kebutuhan, analisis keputusan, desain logis, desain fisik, konstruksi dan pengujian. Subyek penelitian ini adalah pengguna sistem informasi surveilans leptospirosis, yaitu pengelola program leptospirosis, kepala bidang, dan kepala dinas. Penelitian dilaksanakan di Dinas Kesehatan Kota Semarang pada bulan Maret-Juni 2018.

\section{HASIL DAN PEMBAHASAN}


Kegiatan surveilans leptospirosis di Dinas Kesehatan Kota Semarang dimulai dari adanya laporan kasus leptospirosis oleh puskesmas, rumah sakit, kader, masyarakat, atau pasien itu sendiri. Laporan kemudian akan ditindaklanjuti oleh pengelola program leptospirosis dengan melakukan penyelidikan epidemiologi yang berpedoman pada formulir pelacakan leptospirosis. Data yang terkumpul kemudian dicatat, diolah, dan dianalisis sehingga menghasilkan laporan bulanan dan tahunan yang diteruskan kepada kepala bidang dan kepala dinas.

Kendala yang ditemukan berdasarkan wawancara pada pengguna sistem informasi, seperti kurang lengkapnya data yang dimasukkan ke dalam sistem; kesulitan dalam memasukkan, menganalisis, dan mencari data; serta membutuhkan waktu yang lebih lama untuk memperoleh informasi spasial kasus leptospirosis.

Pengembangan sistem informasi surveilans lepstospirosis dilakukan untuk mengatasi permasalahan berdasarkan pada kebutuhan pengguna. Kebutuhan data pengguna, yaitu berasal dari formulir pelacakan leptospirosis, meliputi identitas pasien, gejala klinik, riwayat pengobatan, riwayat pekerjaan, riwayat mandi 30 hari terakhir, riwayat luka, kondisi lingkungan, dan riwayat kontak dengan host dan air kotor. Sistem informasi yang dibutuhkan harus memiliki kemampuan untuk memudahkan proses memasukkan, menganalisis, mengolah dan menyajikan data dengan cepat dan akurat, mampu menggambarkan aspek epidemiologi yang dilengkapi dengan peta dan gambaran faktor risikonya.

\section{Sistem Informasi Surveilans Leptospirosis}

Sistem operasi yang dipilih untuk sistem informasi surveilans leptospirosis adalah sistem operasi Windows. Pemilihan tersebut didasarkan pada pertimbangan bahwa komputer yang tersedia dan layak digunakan di Dinas Kesehatan Kota Semarang menggunakan sistem operasi Windows.

Tools yang digunakan dalam mengembangkan sistem informasi surveilans leptospirosis adalah Adobe Dreamwaver CS3 dengan bahasa pemrograman PHP dan pengelolaan database dengan menggunakan MySQL. Sedangkan dalam pembuatan interface, tools yang digunakan adalah Bootstrap. Tools lain yang dipilih, yaitu ArcGis 10.3 untuk membantu melakukan analisis spasial dengan kategori informasi yang sesuai dengan kebutuhan.

Setelah pemilihan tools, dibuat suatu rancangan sistem informasi surveilans leptospirosis dalam sebuah skema diagram alir data (Data Flow Diagram). Diagram konteks merupakan diagram level pertama dari Data Flow Diagram (DFD) yang menggambarkan keseluruhan sistem berupa aliran data yang masuk dan keluar dari masing-masing entitas. Berikut ini adalah diagram konteks sistem informasi surveilans leptospirosis yang baru: 


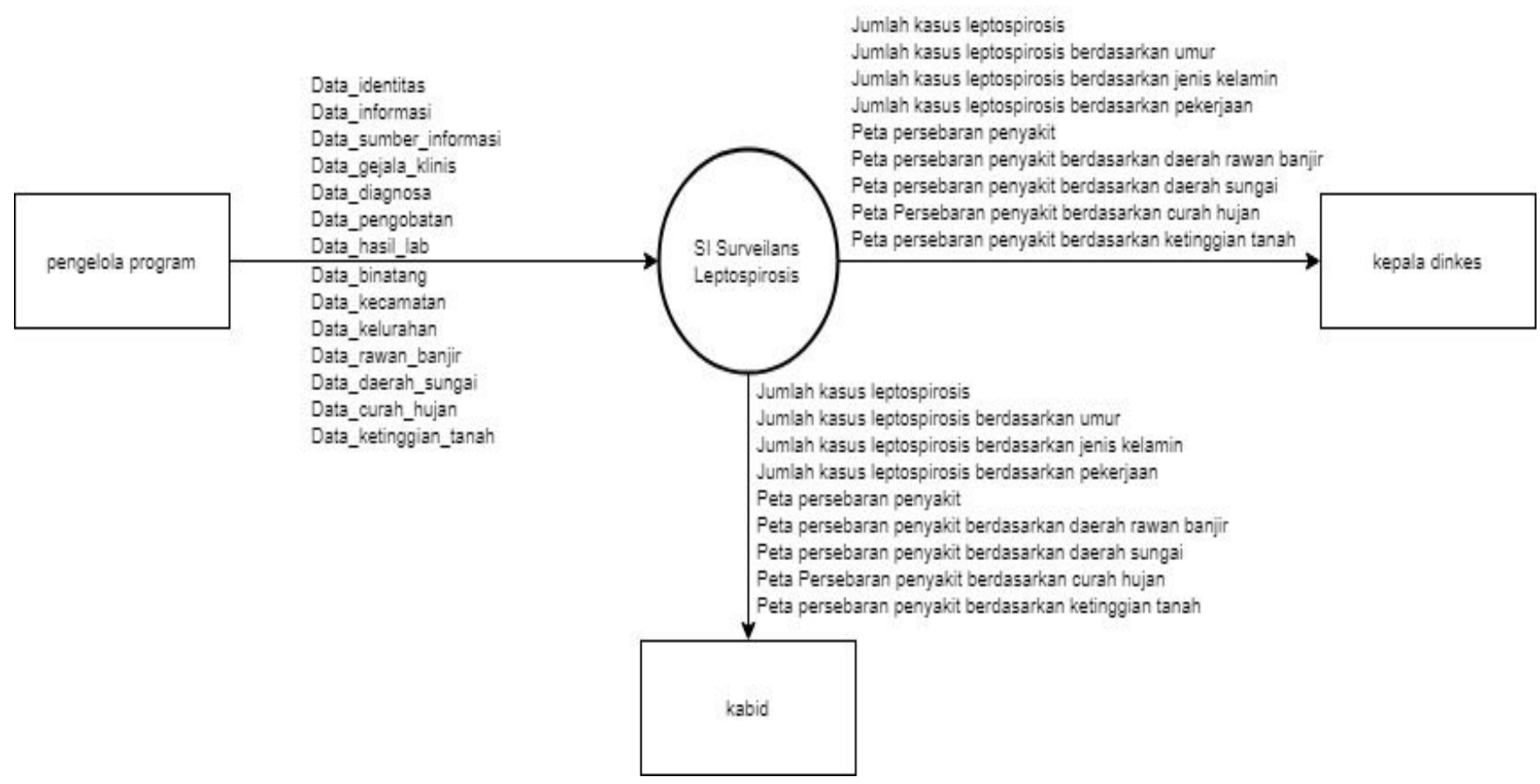

Gambar 1. Diagram Konteks Sistem Informasi Surveilans Leptospirosis (Baru)

Gambar 1 menjelaskan tentang alur input dan output data pada sistem informasi surveilans leptospirosis serta entitas pengguna yang terlibat. Berdasarkan Gambar 1 dapat diketahui bahwa pengguna yang memanfaatkan sistem informasi surveilans leptospirosis adalah pengelola program, kepala bidang, dan kepala dinkes. Pengelola program bertugas untuk memasukkan data ke dalam sistem informasi, sedangkan kepala bidang dan kepala Dinkes menerima informasi yang dihasilkan oleh sistem. Terdapat 6 proses yang terjadi dalam sistem informasi surveilans leptospirosis, yaitu proses setup daerah, setup formulir, input data pada formulir, analisis, menampilkan hasil GIS, dan menghasilkan laporan baik bulanan maupun tahunan.

Sesuai dengan proses pada rancangan tersebut, sistem informasi surveilans leptospirosis memiliki 6 menu utama. Menu Setup Daerah, berfungsi untuk melakukan pengaturan inputan geografis yang dibutuhkan. Sedangkan menu Setup Formulir berfungsi untuk mengatur inputan pada formulir apabila perlu perubahan atau penambahan untuk gejala klinis dan jenis hewan.

Menu berikutnya adalah Formulir, dimana pada menu ini dapat dilakukan input data kasus leptospirosis dengan urutan sub menu yang sesuai dengan formulir pelacakan leptospirosis yang digunakan. Pada menu ini juga dapat dilakukan fungsi edit dan delete serta membuka rekap inputan. Kemudian terdapat menu Analisis untuk menunjukkan hasil olah data ke dalam tabel dan grafik, serta menu Hasil GIS yang menampilkan hasil olah data ke dalam bentuk peta. Terakhir adalah menu Laporan yang berfungsi untuk menampilkan laporan bulanan/tahunan kasus leptospirosis yang dapat langsung dicetak. 
Tampilan menu yang digunakan pada sistem informasi surveilans leptospirosis, meliputi binary menu, multiple selection menu, dan pull-down menu. Menu pada sistem informasi surveilans leptospirosis juga dilengkapi dengan icon, serta gambar yang disertai keterangan. Menu sistem informasi surveilans leptospirosis disesuaikan dengan formulir pelacakan leptospirosis yang telah digunakan saat menjalankan sistem manual.

\section{Uji Coba Sistem Informasi}

Uji coba dimulai dengan pengecekan sistem dari tingkat dasar hingga tingkat sistem secara keseluruhan. Saat memulai proses membangun sistem informasi surveilans leptospirosis, dilakukan pengetesan interaksi antar data dan tabel pada database apakah dapat menghasilkan relasi yang tepat. Tahap selanjutnya dilakukan pengecekan pada sistem terkait dengan tampilan menu apakah telah sesuai dengan formulir masukan dan laporan yang dibutuhkan. Kemudian dilakukan pula tes pada menu dan icon yang terdapat pada sistem, apakah sudah beroperasi atau menjalankan perintah dengan benar. Tahap terakhir mengetes sistem secara keseluruhan apakah sistem dapat bekerja sesuai dengan harapan dan fungsinya.

Setelah validasi sistem informasi surveilans leptospirosis selesai, dilakukan uji coba sistem kepada pengguna. Uji coba ini dilaksanakan selama 4 minggu, dimulai dari tahap pengenalan sistem informasi, simulasi untuk memperlihatkan cara kerja sistem informasi, pelatihan cara pengoperasian, hingga penerapan sistem. Uji coba pada pengguna bertujuan untuk mengetahui kualitas informasi yang dihasilkan dengan pendekatan kualitatif. Kualitas informasi yang dinilai, meliputi aspek kelengkapan, ketersediaan, kemudahan, keakuratan, dan ketepatan waktu.

Berdasarkan hasil wawancara terhadap pengguna tentang kualitas informasi, dapat dianalisis bahwa sistem informasi surveilans leptospirosis telah mampu mengatasi permasalahan dan memenuhi kebutuhan menurut aspek kualitas informasi.

Pada aspek kelengkapan, sistem informasi surveilans yang baru mampu menyediakan informasi pasien, hasil GIS, dan isi laporan yang lengkap. Ketersediaan laporan yang dibutuhkan, akses data, dan keamanan data juga tersedia dengan baik. Proses input, pengolahan, pencarian, dan pemetaan kasus dinilai mudah dilakukan dengan sistem ini. Selain itu, sistem informasi surveilans leptospirosis juga menghasilkan data yang akurat dan tepat waktu.

\section{KESIMPULAN}

Sistem informasi surveilans leptospirosis yang diterapkan sebelumnya memiliki beberapa permasalahan, diantaranya data yang direkam ke dalam sistem kurang lengkap (input); kesulitan dalam akses data, analisis data dan pemetaan kasus (proses); serta tidak lengkapnya informasi yang dihasilkan (output).

Kebutuhan untuk pengembangan sistem informasi surveilans leptospirosis yang baru, antara lain formulir pelacakan leptospirosis (input), proses memasukkan, menganalisis, dan mengolah data yang lebih mudah, cepat, akurat (proses); informasi yang dilengkapi dengan peta dan gambaran faktor risikonya (output). 
Hasil uji coba sistem informasi surveilans leptospirosis menunjukkan bahwa kualitas informasi yang dihasilkan berdasarkan aspek kemudahan, kelengkapan, ketersediaan, keakuratan, dan ketepatan waktu telah dinilai lebih baik dan mampu mengatasi permasalahan yang ada sebelumnya.

\section{UCAPAN TERIMAKASIH}

Penulis mengucapkan terima kasih kepada MIKM FKM UNDIP dan Dinas Kesehatan Kota Semarang atas diijinkannya melakukan penelitian ini.

\section{DAFTAR PUSTAKA}

1. WHO. Human Leptospirosis: Guidance For Diagnosis, Surveillance And Control. Geneva: World Health Organization/ International Leptospirosis Society; 2003.

2. Sekretaris Jenderal Kementerian Kesehatan RI. Profil Kesehatan Indonesia Tahun 2016. Jakarta: Kementerian Kesehatan RI; 2017.

3. Dinas Kesehatan Kota Semarang. Profil Kesehatan Kota Semarang Tahun 2016. Semarang: Dinas Kesehatan Kota Semarang; 2016.

4. Keputusan Menteri Kesehatan Republik Indonesia Nomor 1479 Tahun 2003 tentang Pedoman Penyelenggaraan Sistem Surveilans Epidemiologi Penyakit Menular dan Penyakit Tidak Menular Terpadu.

5. Kementerian Kesehatan Republik Indonesia. Buku Pedoman Penyelidikan dan Penanggulangan Kejadian Luar
Biasa Penyakit Menular dan Keracunan Pangan (Pedoman Epidemiologi Penyakit) Edisi Revisi. Jakarta: Kementerian Kesehatan Republik Indonesia; 2011.

6. Gracie R, Barcellos C, Magalhaes M, Santos RS, Barrocas PRG. Geographical Scale Effects on the Analysis of Leptospirosis Determinants. International Journal of Environmental Research and Public Health, 2014; 11:p.10366-10383.

7. Abass RS, Alla MY, El-Eragi AM. Spatial Risk Analysis of Water Borne Diseases (Bovine Leptospirosis) in the Rive Nile State-Sudan. Journal of Geographic Information System, 2014; 6:p.1-10.

8. Irwansyah E. Sistem Informasi Geografis: Prinsip Dasar dan Pengembangan Aplikasi. Yogyakarta: Digibooks; 2013.

9. Zhang, LQ. Geospatial Informatics Techniques Based Reproductive Health Surveillance System. The International Archives of the Photogrammetry, Remote Sensing and Spatial Information Sciences, 2008; 37(7):p.171-176.

10. Sunaryo S. Sistem Informasi Geografis untuk Pemetaan dan Penentuan Zona Kerawanan Leptospirosis di Kota Semarang. Research and Development Animal Born Deseases Control Station Banjarnegara Central Java, 2009. 